\title{
Feeding an enhanced diet to Holstein heifers during the preweaning period alters steroid receptor expression and increases cellular proliferation
}

\author{
A. J. Geiger, C. L. M. Parsons, and R. M. Akers ${ }^{1}$ \\ Department of Dairy Sciences, Virginia Polytechnic Institute and State University, Blacksburg 24061
}

\begin{abstract}
Preweaning diet and estradiol treatment alters mammary development. Our objectives were to study the effects of diet and estradiol on proliferation of mammary epithelial cells and expression of estrogen receptor $\alpha$ (ESR1) and progesterone receptors (PGR) in these cells. Thirty-six Holstein heifer calves were raised on (1) a control milk replacer fed at $0.44 \mathrm{~kg}$ of powder/ head per day, dry matter (DM) basis (restricted, R; $20.9 \%$ crude protein, $19.8 \%$ fat, DM basis), or (2) an enhanced milk replacer fed at $1.08 \mathrm{~kg}$ of powder/ head per day, DM basis (Enhanced, EH; $28.9 \%$ crude protein, $26.2 \%$ fat, DM basis). Milk replacer was fed for $8 \mathrm{wk}$. At weaning, a subset $(\mathrm{n}=6 /$ diet $)$ of calves were euthanized and had tissue harvested. Remaining calves received estradiol implants $\left(\mathrm{E}_{2}\right)$ or placebo and were euthanized at wk 10 to harvest tissue. Treatments were (1) R, (2) R + $\mathrm{E}_{2}$ (R-E2), (3) EH, and (4) EH $+\mathrm{E}_{2}$ (EH-E2). One day before euthanasia calves were given bromo-2'-deoxyuridine (BrdU; $5 \mathrm{mg} / \mathrm{kg}$ of body weight). At euthanization, mammary parenchyma was removed and fixed. Tissue sections from zone 1 (cisternal), 2 (medial), and 3 (distal) within the mammary gland were stained with hematoxylin and eosin and antibodies to measure expression of ESR1, PGR, and incorporation of BrdU. At wk 8, R-fed calves had more PGR-expressing cells in distal parenchyma; however, PGR expression intensity was greater in EH-fed calves. The proportion of cells expressing ESR1 was not affected by diet, but expression intensity (receptors per positive cell) was greater in $\mathrm{EH}$-fed calves across all zones (62-81\%). Overall, the percent BrdU-positive epithelial cells was 2 and 0.5 fold greater for EH-fed calves in zone 2 and 3 . The proportion of labeled cells was greater in terminal ductal units than in subtending ducts, and treatment effects were more evident in
\end{abstract}

Received February 23, 2017.

Accepted June 7, 2017.

${ }^{1}$ Corresponding author: rma@vt.edu terminal ductal units. At wk 10, calves treated with estradiol had 3.9-fold greater PGR expression intensity. The intensity and percent of cells expressing ESR1 was lowest in estradiol-treated calves. Overall, estradioltreated calves had the greatest number of proliferating epithelial cells. Moreover, in zone 3, EH-E2 calves had a higher percentage of proliferating cells than in all other treatments. Results indicate both diet and estradiol administration alter proliferation rates of the mammary epithelium and that changes in expression of ESR1 and PGR are involved in enhanced mammary development. The data support our hypothesis that enhanced preweaning feeding increases the mammary tissue responsiveness to mammogenic stimulation.

Key words: mammary gland, calf, estrogen receptor, progesterone receptor

\section{INTRODUCTION}

The goal of the replacement heifer industry is to provide the lactating herd with the most profitable animal possible. With replacement rearing accounting for the second largest on-farm expense (Heinrichs, 1993), the need to develop replacement heifers more efficiently is evident.

Much work in the past 2 decades has assessed management of replacement heifers and how these feeding, housing, and care decisions influence the quality of the replacements. However, the area of most emphasis has been nutritional management of the dairy heifer. For some time, a major goal of the replacement industry was to shorten the time needed to transition replacement heifers into the lactating herd. For this to occur, heifer calves must give birth earlier and, in turn, reach puberty and be bred at an earlier age. Because puberty is highly correlated with BW (Sejrsen, 1994), changes in feeding schemes can produce heifers that reach puberty at earlier ages; this requires feeding a diet that encourages greater prepubertal BW gain. Unfortunately, greater prepubertal gains can decrease first-lactation performance by $15 \%$ or more (Radcliff et al., 2000), a number that is considered debatable but for which supporting data does exist (Van Amburgh 
et al., 1998). Therefore, it appears uneconomical to encourage greater BW gain at this time.

However, results from recent research trials suggest that not all portions of the prepubertal period are equal with respect to negative effects. In fact, multiple studies suggest that increased BW gain in replacement heifers during the milk-fed (preweaning) stage is beneficial to health and future performance (Drackley et al., 2007; Soberon et al., 2012). Although many studies indicate that a greater rate of gain during the milk-fed stage of life increases first-lactation milk yield, the mechanisms at play remain largely unknown (Khan et al., 2011).

Meyer et al. (2006a) found that by feeding a higher plane of nutrition early in life, mammary fat pad weights and DNA content of the mammary parenchyma (PAR) increased. In their study, however, differences in PAR disappeared when adjusted for BW. Additionally, Brown et al. (2005) found that providing a higher plane of nutrition to calves in early life resulted in more total PAR tissue, PAR DNA, PAR RNA, and concentrations of DNA and RNA in the mammary gland.

In recent reports (Geiger et al., 2016a) we replicated previous work and showed that a much larger heifer with an increased plane of nutrition (i.e., roughly 20 $\mathrm{kg}$ heavier at weaning) can be attained by feeding 2 distinctly different planes of nutrition during the preweaning phase of life. Moreover, mammary PAR mass was increased 7.3 fold with enhanced preweaning feeding, mammary tissues from enhanced-fed calves were also more responsive to estrogen stimulation, and the biochemical composition of the PAR and mammary fat pad was normal (Geiger et al., 2016b).

The objective of the current study was to assess the effects of 2 different preweaning diets on expression of receptors for mammogenic steroid hormones and the corresponding effects on the proliferation of mammary epithelial cells within the developing mammary gland. A secondary objective was to assess the effect of exogenous estradiol on tissue development, cell proliferation, and expression of the same parameters when exogenous estradiol was provided to these 2 different groups of calves immediately postweaning. It was our hypothesis that providing a greater plane of nutrition preweaning alters expression of estrogen receptor $\alpha$ (ESR1) and progesterone receptor (PGR) in the population of mammary epithelial cells, and that these changes correspond with changes in cellular proliferation within the developing mammary gland. We further hypothesized that calves fed a higher plane of nutrition and given estradiol immediately postweaning would exhibit the greatest rate of cellular proliferation compared with all other treatments. This would support the idea that better nutrition in early life better prepares the mammary gland to respond to mammogenic stimuli.

\section{MATERIALS AND METHODS}

This experiment was conducted under the review and approval of the Virginia Polytechnic Institute and State University Institutional Animal Care and Use Committee (\#14-045-DASC).

\section{Animal Handling and Experimental Design}

The experimental design and animal handling were as previously described (Geiger et al., 2016a). Briefly, Holstein, heifer calves (initial $\mathrm{BW}=39.0 \pm 4.4 \mathrm{~kg}$; initial age $=6.0 \pm 2.0 \mathrm{~d}$ ) were assigned to 1 of 2 experimental milk replacers (MR; $\mathrm{n}=18 / \mathrm{MR}):(1)$ a restricted MR (20.9\% CP, 19.8\% fat, DM basis; Southern States Cooperative Inc., Richmond, VA) fed at $0.44 \mathrm{~kg} /$ head per day, DM basis; or (2) an enhanced MR $(28.9 \%$ CP, $26.2 \%$ fat, DM basis; Land O'Lakes Animal Milk Products Co., Shoreview, MN) fed at $1.08 \mathrm{~kg} /$ head per day, DM basis. Starter (25.6\% CP, $4.0 \%$ fat, DM basis; Southern States Cooperative Inc.) was offered at the end of wk 4 of the trial. A subset of calves $(\mathrm{n}=6$ / diet) were euthanized upon weaning, which occurred at wk 8 , to assess dietary effects on mammary gland development. The remaining calves $(\mathrm{n}=24)$ were either given an estradiol $\left(\mathbf{E}_{2}\right)$ implant (Compudose, Elanco Animal Health, Greenfield, IN) or a placebo implant at weaning. This produced treatment groups $(\mathrm{n}=6 /$ treatment) of (1) calves restricted-fed and given a placebo implant (R), (2) calves restricted-fed and given an $\mathrm{E}_{2}$ implant (R-E2), (3) enhanced-fed calves given a placebo implant (EH), and (4) enhanced-fed given an $\mathrm{E}_{2}$ implant (EH-E2). After 2 wk of $\mathrm{E}_{2}$ or placebo treatment, all remaining animals were euthanized and mammary tissue was harvested to assess the effect of $\mathrm{E}_{2}$ on calves fed the 2 different diets. This euthanasia and harvest occurred at wk 10 and calves were given i.v. injections of bromo-2'-deoxyuridine (BrdU) at a dose of $5 \mathrm{mg} / \mathrm{kg}, 24 \mathrm{~h}$ before sampling.

\section{Mammary Tissue Collection and Sample Preparation}

Animal euthanasia and sample preparation are outlined in detail in a previous work (Geiger et al., 2016a,b). The right fore quarter of the udder was used to collect tissue samples that were fixed for immunohistochemistry. Briefly, the dissected parenchymal mass with the teat attached was partially bisected or butterflied (depending on size) and immersed in a container of fixative, as described in a previous study (Tucker et al., 2016). Examples of dissected, fixed tissues are shown in Geiger et al. (2016a). After fixation, these tissues were subsampled to provide PAR from near the teat (zone 1), midway (zone 2) to the outer region 
of the parenchymal, and at the margin between the outermost PAR region and the surrounding mammary fat pad (zone 3). For some of the R heifers, the PAR mass was too small justify subsampling, thus embedded tissues encompassed each of the 3 tissue regions in individual paraffin blocks. For analysis, $5-\mu$ m-thick sections were prepared, collected onto microscope slides, deparaffinized, and rehydrated as previously reported (Beaudry et al., 2016).

\section{Primary and Secondary Antibody Incubation}

Retrieval of antigens, incubations, and immunohistochemistry to detect ESR1-, PGR-, and BrdU-labeled cells was done as described in a previous study for our laboratory (Tucker et al., 2016) using the same lots of reagents. Briefly, after aspiration of CAS Block (Life Technologies, Grand Island, NY), approximately $50 \mu \mathrm{L}$ of fresh, diluted primary antibody solution (1:200, 1:50, and 1:100 for ESR1, PGR, and BrdU, respectively) was added to each tissue section as appropriate. Slides were incubated with primary antibody overnight at $4^{\circ} \mathrm{C}$ in a humidified chamber. One or 2 sections per slide served as a negative control and received CAS Block as a substitute for primary antibody solution. The remaining sections on the slide $(n \geq 2)$ served as replicates for the desired labeling or staining.

After removal of the primary antibody via vacuum aspiration, the slides were rinsed in PBS 3 times for 5 min each time. All tissue sections (including negative controls) received $50 \mu \mathrm{L}$ of the diluted secondary antibody mixture (1:200) and were incubated for 60 min at room temperature. Secondary antibody solutions were then aspirated and slides were rinsed in PBS $(3 \times$ for 5 min each). Then, PAP pen circles (Ted Pella Inc., Redding, CA) were removed with a cotton swab dipped in xylene substitute. Slides were rinsed again in PBS, aspirated to remove excess liquid, and coverslips were mounted using Slowfade Gold antifade reagent containing 4',6-diamidino-2-phenylindole (DAPI), a counter stain that stains all cell nuclei (Life Technologies). Completed slides were kept overnight in the dark before imaging.

\section{Immunohistochemical Mammary Analyses}

Photomicrographs were taken within $48 \mathrm{~h}$. Images were acquired using a Nuance FX multispectral imaging system (Thermo Fisher Scientific, Waltham, MA) mounted on a Nikon Eclipse 800 epi-fluorescence microscope fitted with Plan Fluor $20 \times$ and $40 \times$ objectives (Nikon Instruments Inc., Melville, NY). Excitation light was generated using a mercury lamp and standard filter cubes fitted with long pass emission filters. The Nuance system was configured to use multiple customized emission settings for each fluorophore. At least 5 photomicrographs were taken per stained section on each slide.

\section{ImagePro Analysis}

Image analyses were conducted similar to that of Tucker et al. (2016). All of the tagged image file format (TIFF) images from the Nuance System were converted into joint photographic experts groups (JPEG) for use by the ImagePro software (Media Cybernetics Inc., Rockville, MD). This allowed for reduction of background and ready identification of positive cells. The individual files for each image were pseudo-colored: DAPI blue and ESR1 red, or DAPI blue, PGR red, and BrdU green. The individual files were used to create composite images for display or evaluation.

Individual epithelial areas within each composite image were outlined for evaluation. These areas of interest were determined and defined by having at least 20 epithelial cells within the general PAR area; there were 3 to 4 areas selected per image.

Each area of interest was used to determine 4 response variables. First, the total number of epithelial cells was counted. These were the cells whose nuclei were stained with DAPI. Second, cells that expressed ESR1 or PGR were also counted. Finally, BrdU-positive cells were counted. These 4 response variables were combined with area measures to determine DAPI-, ESR1-, PGR-, and BrdU-positive cells on a tissue area basis as well as the proportion of positive cells as a portion of total epithelial cells. This evaluation was done for each zone within each calf. Additionally, for BrdU labeling, for tissues in zone 3 , areas of interest were divided into 2 elements for comparison: (1) subtending ducts (SubD) and (2) terminal ductal units (TDU). Examples of a TDU and its SubD are illustrated in Brown et al. (2005). Averages were then calculated and treatments compared. All the counts were recorded in a Microsoft Excel (Microsoft Corp., Redmond, WA) spreadsheet for subsequent statistical analysis.

\section{Image Receptor Intensity Analysis}

Photomicrographs were evaluated by identifying at least 10 cells in each image that expressed ESR1 or PGR. These cells were selected at random, but 1 criterion was that they were distinct from surrounding cells. Tissues from all zones were used to evaluate ESR1 and PGR expression intensity, as described by Tucker et al. (2016). ImagePro software was then used to measure 
the mean intensity of each selected cell nucleus. The same photomicrographs used to count the ESR1 and PGR expressing cells were used for this analysis, and all cells selected were within previous identified epithelial clusters. Examples of ESR1- and PGR-positive epithelial cells and the procedure to measure expression intensity appear in recent publications (Velayudhan et al., 2015; Tucker et al., 2016).

\section{Statistical Analysis}

Statistical analysis was conducted as previously described (Geiger et al., 2016a,b) using PROC GLIMMIX in SAS (ver. 9.4, SAS Institute Inc., Cary, NC). All data were checked for normality before any statistical procedures were performed. For all analyses, main effects included treatment, mammary gland zone $[1$ (cisternal), 2 (medial), or 3 (distal)], and the associated interactions. The calf was treated as a random variable for a given dependent observation within a zone (i.e., multiple observations per zone). Nonsignificant interactions were removed from the model when appropriate. Treatment, zone, and their interaction were treated as fixed effects, whereas residual error was treated as a random effect. Calf data from the 8- and 10-wk animal harvest were treated as different experiments and not compared across harvest dates. Data from week 8 were used to assess the effect of plane of nutrition and data from wk 10 were used to assess the effect of diet, estrogen, and their interaction. Significance was declared at $P<0.05$ and tendencies are discussed at $0.05<P$ $<0.10$.

\section{RESULTS AND DISCUSSION}

\section{ESR1 and PGR Expression}

Analysis of both ESR1 and PGR expression was completed on both a tissue-area basis (positive cells per $\mu \mathrm{m}^{2}$ of epithelium) and on a per-cell basis. Both estimates showed essentially the same treatment-related patterns of response. However, because expression of responses as a percent of the total cell population (epithelial cells in our case) are most common, these data are given. The importance of estrogens and progesterone in control of mammary growth is well established; however, understanding relationships between numbers or intensity of ESR1- and PGR-positive cells with changes in the degree or pattern of mammary gland growth and cell proliferation in the bovine is not.

At weaning, the percentage of epithelial cells expressing ESR1 was not affected by diet (Figure 1), regardless of zone. Expression of ESR1 was, however, different depending on zone $(P<0.01)$; expression was greatest

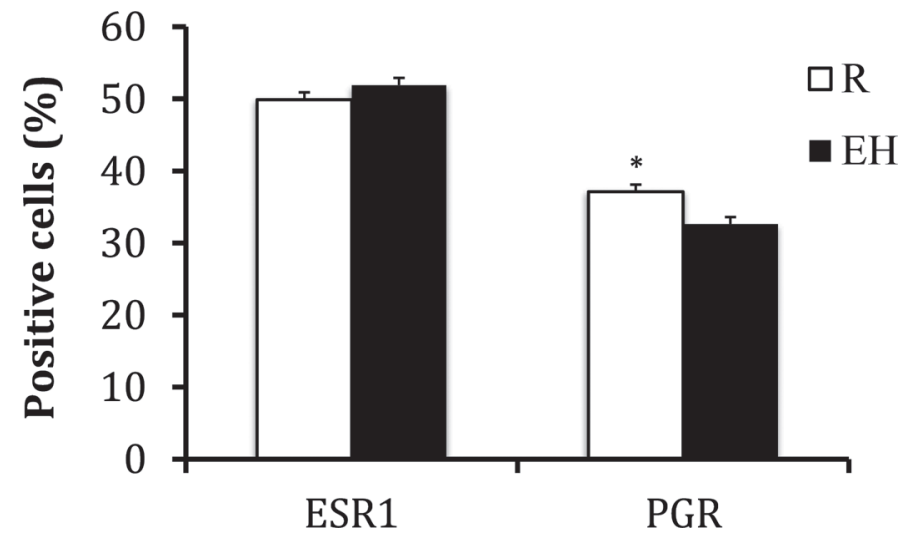

Figure 1. Estrogen receptor- $\alpha$ (ESR1) and progesterone receptor (PGR) expression in the mammary epithelial cells of Holstein heifer calves fed either a restricted $(\mathrm{R})$ or enhanced $(\mathrm{EH})$ diet preweaning. ${ }^{*} P \leq 0.01$. Error bars are SEM.

in zone $3(57.9 \%)$, lower in zone $2(51.9 \%)$ and lowest in zone $1(43.4 \%)$. At weaning, the overall percentage of epithelial cells expressing PGR was greater for R calves compared with EH calves (Figure 1), most likely due to an especially large difference in PGR-positive cells in zone 3 (17.2 vs. $9.9 \%$ for $\mathrm{R}$ and $\mathrm{EH}$, respectively; $P$ $<0.01)$. Additionally, both zone 2 and 3 had greater PGR expression than zone 1 , but were not different from each other ( 40.3 and 35.0 vs. $28.5 \%$ for zones 3,2 , and 1 , respectively; $P<0.01)$.

After weaning, half of the remaining calves from each diet received estradiol for $2 \mathrm{wk}$. The administration of estradiol influenced the percentage of cells expressing ESR1, but postweaning diet did not. Calves receiving estradiol had a substantially lower proportion of ESR1expressing cells across all zones (Table 1); however,

Table 1. Steroid receptor expression of mammary epithelial cells of Holstein heifer calves fed either an enhanced or a restricted diet preweaning with or without exogenous estrogen immediately postweaning

\begin{tabular}{lccccc}
\hline Item & $\mathrm{R}^{1}$ & $\mathrm{R}-\mathrm{E}^{2}$ & $\mathrm{EH}^{3}$ & $\mathrm{EH}^{2} 2^{4}$ & SEM \\
\hline $\mathrm{ESR}^{5}(\%)$ & $51.8^{\mathrm{a}}$ & $32.7^{\mathrm{b}}$ & $51.6^{\mathrm{a}}$ & $35.8^{\mathrm{b}}$ & 2.10 \\
$\mathrm{PGR}^{6}(\%)$ & 34.1 & 29.4 & 32.7 & 30.3 & 0.30 \\
\hline
\end{tabular}

$\overline{\mathrm{a}, \mathrm{b}}$ Differing superscripts within a row indicate treatment differences $(P<0.05)$.

${ }^{1} \mathrm{R}=$ Calves fed restricted milk replacer $(20 \% \mathrm{CP}, 20 \%$ fat $)$ at a rate of $0.45 \mathrm{~kg} / \mathrm{d}$.

${ }^{2} \mathrm{R}$-E2 $=$ Calves fed restricted diet and given estrogen for 2 wk postweaning.

${ }^{3} \mathrm{EH}=$ Calves fed enhanced milk replacer $(28 \% \mathrm{CP}, 25 \%$ fat $)$ at a rate of $1.13 \mathrm{~kg} / \mathrm{d}$.

${ }^{4} \mathrm{EH}-\mathrm{E} 2$ = Calves fed enhanced $\mathrm{EH}$ and given estrogen for 2 wk postweaning.

${ }^{5}$ Estrogen receptor $\alpha$.

${ }^{6}$ Progesterone receptor. 
neither presence of estradiol or diet affected PGR expression on a per-cell basis (Table 1).

Previous work assessing the effects of preweaning diet on ESR1 and PGR expression is scarce. Brown et al. (2005) fed either a moderate $(21.3 \%$ CP, $21.3 \%$ fat fed at $1.1 \% \mathrm{BW} ; 20.5 \% \mathrm{CP}$ starter) or high plane of nutrition diet $(30.3 \% \mathrm{CP}, 15.9 \%$ fat fed at $2.0 \%$ BW; $25.0 \%$ $\mathrm{CP}$ starter) to Holstein calves during the preweaning period. Brown et al. (2005) showed that preweaning diet did not influence the percentage of cells expressing ESR1 in either the SubD or TDU of the mammary PAR; these data agree with our results, but those researchers did not assess PGR expression. To the best of our knowledge, PGR expression has not been assessed in an experiment involving differential feeding such as ours. Reasons for the modest increase in percentage PGR expression at weaning are unknown but likely of minimal biological relevance.

Regardless of diet, calves given estradiol postweaning experienced a substantial decrease in the proportion mammary epithelial cells expressing ESR1. This may reflect receptor downregulation (as suggested by differences in intensity of ESR1 expression), as discussed below; alternatively, this may also reflect the dramatic increase in cell number following estradiol treatment (i.e., the increase in mammary mass and DNA content; Geiger et al., 2016b), essentially a dilution of the population of ESR1-positive cells by growth-competent ESR1-negative epithelial cells. This conjecture is supported by the findings of Capuco et al. (2002), demonstrating that nearly all proliferating epithelial cells in the bovine mammary gland are ESR1-negative. We also noted a similar finding in mammary tissue from older heifers dual labeled for BrdU and ESR1 (Velayudhan et al., 2015) or ESR1 and Ki67 (Tucker et al., 2016).

Our results are in agreement with Meyer et al., (2006c), who found that, regardless of ovarian status (ovariectomized or intact), both ESR1 expression and ESR1 transcript abundance were decreased when exogenous estradiol was administered. Interestingly, the opposite occurred in ovariectomized heifers not supplemented with exogenous estradiol; that is, the proportion of ESR1-positive cells was greater in ovariectomized compared with control animals (Berry et al., 2003). However, Velayudhan et al., (2015) noted no change in percentage of cells expressing ESR1 after ovariectomy. Differences may reflect differences in the age at ovariectomy or length of time between ovariectomy and tissue collection. Tucker et al. (2016) also reported that the percent of mammary cells expressing ESR1 was unaffected in calves treated with the antiestrogen tamoxifen, but the intensity of ESR1 expression was 6.2 -fold lower in tamoxifen-treated heifers.
Data showing the influence of estradiol on PGR expression in bovine mammary gland is scarce, although PGR is a recognized estrogen-responsive gene (Horwitz et al., 1978). This alone makes the fact that estradiol administration did not change the percentage of PGR expressing cells interesting. However, this result is in agreement with Meyer et al. (2006c), who did not find an influence of estradiol administration on PGR mRNA expression in mammary PAR tissue regardless of ovarian status. In contrast, Velayudhan et al., (2015) found that PGR-expressing epithelial cells were completely absent in heifers $30 \mathrm{~d}$ after ovariectomy. In a related study, Tucker et al. (2016) found no effect of tamoxifen treatment on the percentage of cells expressing PGR, but that the intensity of PGR expression was greater in tamoxifen-treated calves.

\section{ESR1 and PGR Expression Intensity}

Although the percentage of cells expressing ESR1 was unaffected by dietary treatment at weaning, the intensity of ESR1 expression was affected. Expression intensity is a measure of the relative number of receptors per positive cell. Calves on the EH treatment had overall greater $(P<0.001)$ ESR1 expression intensity (Figure 2), and the response differential was consistent across all zones. Overall ESR1 expression intensity was also affected by zone, with zone 3 cells having decreased ESR1 expression intensity compared with zones 1 and 2 (1,686 vs. 2,205 and 2,219 for zones 3,1 , and 2 , respectively; $P<0.05)$. The overall PGR expression intensity was slightly higher in enhanced-fed calves (Figure 2). This differential was also consistent across all zones,

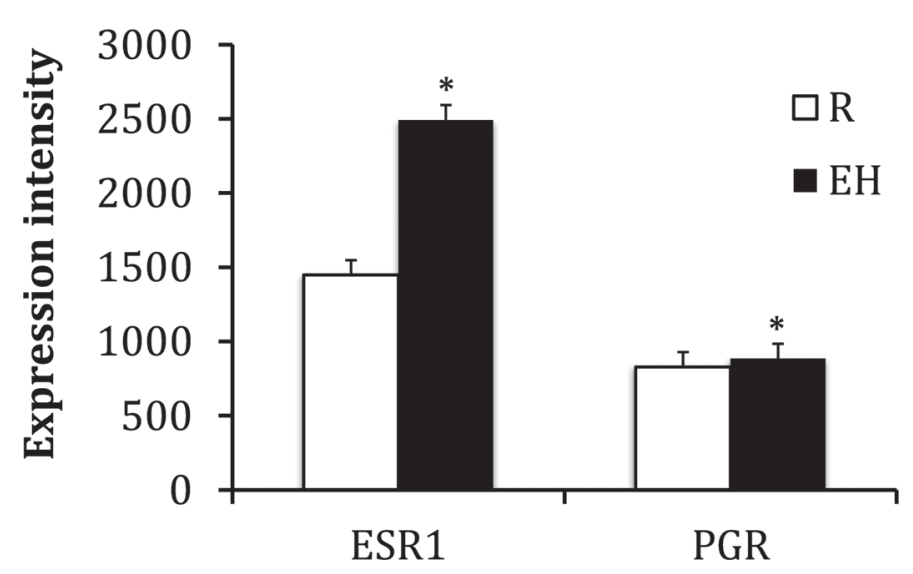

Figure 2. Estrogen receptor- $\alpha$ (ESR1) and progesterone receptor (PGR) expression intensity (arbitrary units) in mammary epithelial cells of Holstein heifer calves fed either a restricted $(\mathrm{R})$ or enhanced (EH) diet preweaning. ${ }^{*} P \leq 0.01$. Error bars are SEM. 
but we found no overall zone effect for PGR expression intensity.

The ESR1 expression intensity was affected by postweaning treatments. Calves on the $\mathrm{EH}$ treatment had higher $(P<0.01)$ expression intensity than all other treatments (Table 2). Moreover, the increased expression in $\mathrm{EH}$ animals compared with $\mathrm{R}$ animals at the time of weaning was still present and somewhat greater at the second sample period (1.6 and 1.9 fold, respectively). Administration of estradiol consistently decreased the intensity of ESR1 expression in both R and EH group animals; moreover, responses were consistent across all zones and interactions were not detected.

The PGR expression intensity was not affected by diet ( $\mathrm{R}$ vs. EH) at the postweaning collection period. Calves receiving estradiol postweaning had greater PGR expression intensity (3-fold) compared with calves that did not receive estradiol (Table 2), with the greatest difference present in zone 1. Postweaning PGR expression intensity was greatest $(P<0.01)$ in zone 1 $(2,177 ; P<0.01)$, followed by zone $3(1,567)$ and zone $2(1,105)$.

To our knowledge, Velayudhan et al. (2015) were the first to measure the intensity of ESR1 and PGR expression in the bovine mammary gland via quantitative image analysis. As recently described (Ellis et al., 2012, Safayi et al., 2012), such data are unique and valuable because they allow the measurement of receptor protein expression in populations of clearly identified cells in the developing mammary gland. This is in contrast with most protein or gene expression studies, which rely on isolation of proteins or mRNA from tissues that contain cells other than epithelial cells or lack of definition of specific populations of epithelial cells (i.e., luminal, medial, basal, myoepithelial) that are being measured. Others have reported the presence of ESR1and PGR-expressing cells, their locations within the developing bovine mammary gland, and proportions of positive cells (Schams et al., 2003; Meyer et al., 2007); however, we believe our report to be the first to assess ESR1 and PGR expression intensity in the mammary gland of calves fed differing diets or given exogenous estradiol.

Of additional interest is the fact that ESR1 expression intensity was lowest in mammary PAR zone 3 (furthest from teat), which may be indicative of the fact that ESR1 is not expressed in proliferating epithelial cells (Capuco et al., 2002). Although the proportion of cells expressing ESR1 was not altered by dietary treatment, functionality as judged by the number of receptors per cell (i.e., expression intensity) was greater in well-fed calves. Knowing the importance of estrogen and its receptor to the mammary gland and its develop-
Table 2. Steroid receptor expression intensity (arbitrary units) in mammary epithelial cells from Holstein heifer calves fed either an enhanced or restricted diet preweaning with or without exogenous estrogen immediately postweaning

\begin{tabular}{lrrrrc}
\hline Item & $\mathrm{R}^{1}$ & $\mathrm{R}-\mathrm{E} 2^{2}$ & $\mathrm{EH}^{3}$ & $\mathrm{EH}^{\mathrm{E}} 2^{4}$ & $\mathrm{SEM}$ \\
\hline $\mathrm{ESR}^{5}$ & $1,801^{\mathrm{a}}$ & $1,002^{\mathrm{b}}$ & $3,446^{\mathrm{c}}$ & $1,171^{\mathrm{b}}$ & 569 \\
PGR $^{6}$ & $696^{\mathrm{a}}$ & $2,584^{\mathrm{b}}$ & $801^{\mathrm{a}}$ & $2,385^{\mathrm{b}}$ & 109 \\
\hline
\end{tabular}

${ }^{\mathrm{a}-\mathrm{c}}$ Differing superscripts within a row indicate treatment differences $(P<0.01)$.

${ }^{1} \mathrm{R}=$ Calves fed restricted milk replacer $(20 \% \mathrm{CP}, 20 \%$ fat $)$ at a rate of $0.45 \mathrm{~kg} / \mathrm{d}$.

${ }^{2} \mathrm{R}$-E2 $=$ Calves fed restricted diet and given estrogen for 2 wk postweaning.

${ }^{3} \mathrm{EH}=$ Calves fed enhanced milk replacer $(28 \% \mathrm{CP}, 25 \%$ fat $)$ at a rate of $1.13 \mathrm{~kg} / \mathrm{d}$.

${ }^{4} \mathrm{EH}-\mathrm{E} 2$ = Calves fed enhanced $\mathrm{EH}$ and given estrogen for 2 wk postweaning.

${ }^{5}$ Estrogen receptor $\alpha$.

${ }^{6}$ Progesterone receptor.

ment (Capuco and Akers, 2010), this increase in ESR1 expression intensity in enhanced-fed calves supports the idea that these calves are better able to respond to mammogenic hormone stimulation. Knowledge that stimulation of ESR1 receptors is likely important in the induction of other mammogenic signals [e.g., IGF-I and its receptor (Berry et al., 2001] support this presumed relationship. It is likely that changes in ESR1 and PGR expression are linked with corresponding changes in IGF-I axis molecules (local tissue IGF-I, IGF-I receptors, and IGF-I binding proteins) to explain dietary mediation of mammary growth in these heifers; however, it is important to note that we did not measure IGF-I axis molecules in the current study. On the other hand, direct evidence links feeding regimens to alteration of the expression of IGF-I axis molecules in the developing bovine mammary gland (Purup et al., 2000; Thorn et al., 2008) as well as the mitogenic potency of extracts from prepubertal calves (Weber et al., 1999, 2000). Consequently, a cascade of connected events, linked with increased expression of ESR1, at least partially explains the improved mammary development in calves with enhanced nutrition. In support of a relationship between ESR1 signaling and mammary growth in heifers, Tucker et al. (2016) measured a 6-fold decrease in the intensity of ESR1 expression in heifers treated with tamoxifen, which corresponded with a $50 \%$ reduction in mammary parenchymal DNA. However, the fact that mammary growth was stimulated in heifers given exogenous estradiol (Geiger et al., 2016b), despite a corresponding decrease in the intensity of ESR1 expression (Table 2), indicates this association is complex. For example, perhaps the lower expression of ESR1 is compensated for by increased circulation of estradiol. 
Expression intensity of PGR was numerically greater in EH-fed calves and 2.9 to 3.7 fold greater after treatment with estradiol (Table 2). Although progesterone and its receptor are important to mammary gland development, at least after puberty, mammary tissue of prepubertal heifers is unresponsive to exogenous progesterone (Woodward et al., 1993). Thus, the role of PGR in peripubertal heifers is not well characterized.

\section{Mammary Epithelial Cell Proliferation}

Mammary epithelial cell proliferation was determined using BrdU incorporation. At weaning, the overall percent of BrdU-labeled epithelial cells across all zones was $60 \%$ greater $(P<0.01)$ in $\mathrm{EH}$ calves (Figure 3 ). When considered by zone, BrdU expression was similar between diets in zone 1 , but 50 and $200 \%$ greater $(P$ $\leq$ 0.01) for EH-fed calves compared with R-fed calves for tissue in zone 2 and 3 , respectively. In addition, we found an overall zone effect $(P<0.05)$ of 10.2, 12.8, and $14.0 \%$, for zones 1,2 , and 3 , respectively. Because overall labeling was highest in zone 3 , we separated epithelial structures for zone 3 samples into SubD and TDU for a more detailed evaluation (Brown et al., 2005). In both EH- and R-fed calves, BrdU incorporation was greater in TDU than in SubD (Figure 4). Interestingly, we found no difference in labeling index between $\mathrm{R}$ and $\mathrm{EH}$ heifers within SubD, but the labeling of TDU nearly doubled $(P<0.001)$ in EH-fed heifers (Figure 4). In retrospect, overall differences in the rate of cell proliferation between SubD and TDU correspond with the very high BrdU labeling rates evident in the 3-dimensional reconstructions presented by Capuco et al. (2002) for mammary tissue samples collected from prepubertal heifers given exogenous es-

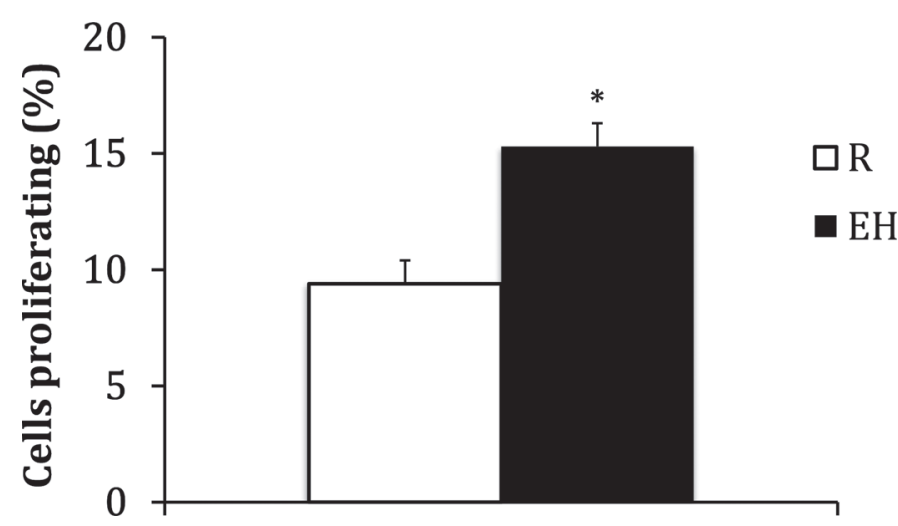

Figure 3. Mammary epithelial cell proliferation in Holstein heifer calves fed either a restricted $(\mathrm{R})$ or enhanced $(\mathrm{EH})$ diet preweaning. $* P \leq 0.01$. Error bars are SEM. trogen. Given these inherent differences in the rate of proliferation between SubD and TDU, measurement of overall rates of epithelial cell proliferation underestimate the growth within the most active regions of the developing ductal structures. This is analogous to the extremely high rates of cell grown observed within the endbud structures of the prepubertal rodent mammary gland (Russo et al., 1999; Paine and Lewis, 2017).

Postweaning, overall BrdU labeling remained greater $(P<0.01)$ in EH-fed calves compared with R-fed calves (Table 3). Moreover, estradiol administration increased cell proliferation in both $\mathrm{R}$ and $\mathrm{EH}$ calves (Table 3). The highest overall incorporation $(19.4 \%)$ was in $\mathrm{EH}$ calves given estradiol. This value was higher than for all other groups. As noted with tissues collected at weaning, there was an overall zone effect $(P<0.05)$ for proliferation in tissues collected at the wk 10 slaughter. Incorporation was highest in zone $3(13.3,14.4$, and $17.1 \%$ for zones 1,2 , and 3 , respectively).

Detailed analysis of zone 3 labeling (SubD vs. TDU) yielded interesting results. Specifically, no treatment differences were noted for BrdU incorporation for epithelial cells within zone 3 SubD $(10.4,10.6,10.4$, and $10.7 \%$ for R, R-E2, EH, and EH-E2, respectively). For all treatments except $\mathrm{R}$-fed calves, the percentage of labeled cells was markedly higher $(P<0.01)$ in TDU than in the SubD (26.0 vs. $10.6,21.2$ vs. 10.4 , and 35.7 vs. $10.7 \%$ for R-E2, EH, and EH-E2, respectively). For R-fed calves, the percentage of labeled cells was numerically greater in TDU than in the SUBD $(12.0$ vs. $10.0 \%)$, but the difference was nonsignificant $(P<$ 0.05). The highest average labeling measured for any

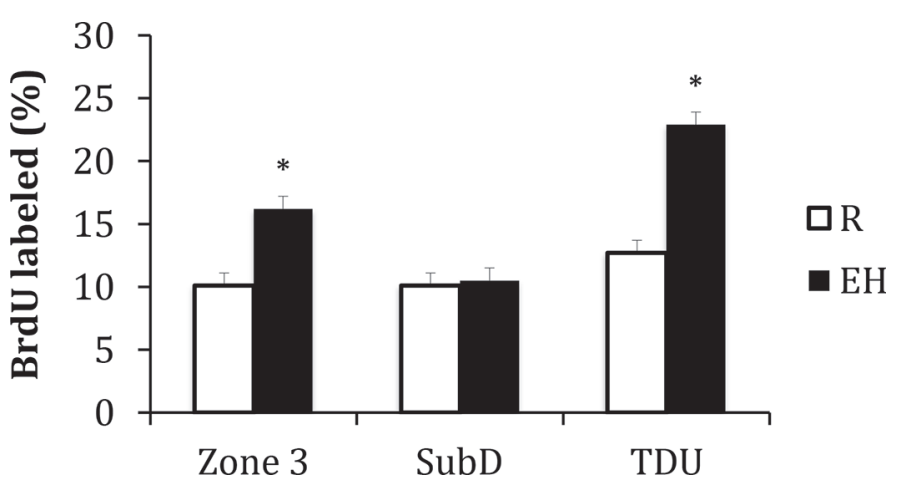

Figure 4. Mammary epithelial cell proliferation in Holstein heifer calves fed either a restricted (R) or enhanced (EH) diet preweaning. Bars on the left indicate the overall labeling index of mammary epithelial cells in zone 3. Middle bars indicate the labeling index for epithelial cells within subtending ducts (SubD) for zone 3. Bars on the right indicate labeling index for epithelial cells within zone 3 terminal ductal units (TDU). Error bars are SEM. BrdU = bromo-2'-deoxyuridine. 
Table 3. Percentage of epithelial cells proliferating in the mammary gland parenchyma of heifers fed either an enhanced or restricted diet preweaning with or without exogenous estrogen immediately postweaning

\begin{tabular}{lcc}
\hline Treatment & $\begin{array}{c}\text { Cellular } \\
\text { proliferation }^{1}(\%)\end{array}$ & SEM \\
\hline $\mathrm{R}^{2}$ & $9.8^{\mathrm{a}}$ & 0.98 \\
$\mathrm{R}^{-E} 2^{3}$ & $17.3^{\mathrm{c}}$ & 0.92 \\
$\mathrm{EH}^{4}$ & $13.2^{\mathrm{b}}$ & 0.95 \\
$\mathrm{EH}^{\mathrm{b}} 2^{5}$ & $19.4^{\mathrm{d}}$ & 1.01 \\
\hline
\end{tabular}

${ }^{\mathrm{a}-\mathrm{d}}$ Differing superscripts within a column indicate treatment differences $(P<0.01)$.

${ }^{1}$ Cellular proliferation determined by bromo-2'-deoxyuridine incorporation.

${ }^{2} \mathrm{R}=$ Calves fed restricted milk replacer $(20 \% \mathrm{CP}, 20 \%$ fat $)$ at a rate of $0.45 \mathrm{~kg} / \mathrm{d}$.

${ }^{3} \mathrm{R}-\mathrm{E} 2=$ Calves fed restricted diet and given estrogen for 2 wk postweaning.

${ }^{4} \mathrm{EH}=$ Calves fed enhanced milk replacer $(28 \% \mathrm{CP}, 25 \%$ fat $)$ at a rate of $1.13 \mathrm{~kg} / \mathrm{d}$.

${ }^{5} \mathrm{EH}-\mathrm{E} 2=$ Calves fed enhanced $\mathrm{EH}$ and given estrogen for 2 wk postweaning.

tissue examined was for TDU in zone 3 of EH-E2treated calves $(35.7 \%)$.

Previous work has assessed the effect of preweaning diet on mammary epithelial cell proliferation. Brown et al. (2005) noted lower Ki67 labeling in both the SubD and TDU in heifers fed a high plane of nutrition diet preweaning. This was attributed the fact that heifers fed the high plane of nutrition diet had relatively more mature ductular structures and, thus, were not proliferating as actively as heifers fed the moderate diet. In another study Daniels et al., (2009b) reported no difference in Ki67 labeling due to preweaning diet. Meyer et al. (2006b) fed heifers differing diets (starting at $10 \mathrm{~d}$ of age) and harvested heifers in $50-\mathrm{kg}$ increments of $\mathrm{BW}$ (i.e., at the same physiological, not chronological, age) to evaluate effects of diet on mammary development. Heifers were fed either an enhanced (29\% CP, $19 \%$ fat) or a restricted $(22 \% \mathrm{CP}, 21 \%$ fat $)$ diet targeting 950 or $650 \mathrm{~g} / \mathrm{d}$ of BW gain, respectively. They reported that BrdU labeling was increased for heifers fed the enhanced diet by nearly 2-fold at a common BW of 100 $\mathrm{kg}$. However, differences no longer existed at heavier weights, and BrdU labeling decreased as BW at harvest increased.

In the current study, we measured a much greater percentage of BrdU incorporation than reported previously (Brown et al., 2005; Meyer et al. 2006b,c; Daniels et al., 2009a,b); reasons for this difference are unknown. It may be that TDU structures were more common in prepared tissue sections. Differences between SubD and TDU labeling suggest this possibility. Regardless, it is important to note that the increased response to treat- ment with estradiol confirms numerous other reports (Woodward et al., 1993; Capuco et al., 2002; Meyer et al., 2006b,c). Relative differences due to dietary treatments and variation between studies likely reflect differences in extremes of dietary treatments (rather large in our study) as well as age at the time of sampling.

The marked differences in proliferation between SubD and TDU in our experiment suggests that studies that evaluate simple overall rates of epithelial cell proliferation might well miss more modest treatment differences. That is, if the rate of proliferation in SubD and other major ducts exhibit a minimal treatment response, and the populations of cells in these structures make up most the cells evaluated, treatment differences driven by changes in proliferation of in TDU would not be detected. This might explain the generally robust positive responses noted after treatment with estradiol compared with lesser affects caused by variations in feeding treatments. Indeed, the 3-dimensional images from Capuco et al., (2002) clearly illustrate the pronounced labeling of TDU compared with other ductal structures after acute treatment with estradiol. Moreover, the higher proliferation rate following estrogen treatment was consistent for tissue collected in multiple regions of the mammary gland, as seen in Capuco et al., (2002). At a minimum, our findings strongly suggest studies that evaluate effects of diet or other treatments on mammary cell proliferation in heifers and calves should focus on changes in proliferation of the TDU in the developing mammary gland.

Overall, our results indicate that feeding an enhanced diet in early life of calves increases mammary growth by particularly increasing proliferation of TDU cells. The importance of estradiol to mammary gland development in dairy cattle is evident. Our data suggest that enhanced feeding of preweaned heifers does indeed improve the capacity of the mammary gland to respond to mammogenic stimulation. This suggests that enhancedfed heifers are better prepared to respond to increases in mammogenic hormones and growth factors with the approach of puberty.

Our data and review of the literature specific to the bovine suggest that regulation of both the proportion of mammary cells expressing ESR1 and PGR as well as the level of expression in positive cells is complex and not well understood. At a minimum, it is reasonable to conclude that estrogen and progesterone both positively affect mammary development, but the interplay between these receptors to regulate mammary development is mysterious. As shown by Capuco et al. (2002), the population of proliferating epithelial cells in the heifer mammary gland are generally not the same populations of cells that express ESR1. This supports 
the idea that ESR1 signaling solicits localized agents that ultimately induce proliferation of cells within the local tissue environment.

\section{CONCLUSIONS}

Data herein allow us to expand upon previous data indicating that feeding a higher plane of nutrition preweaning beneficially affects BW gain, frame size, and mammary gland growth without compromising PAR composition. The purpose of the present work was to understand mechanisms involved. Clearly, calves fed an enhanced diet have mammary epithelium that is more actively proliferating, and these calves are better able to respond to mammogenic stimuli. The particular importance of the TDU in progressive mammary development is emphasized by the dramatic treatment responses of the epithelial cells in these structures. In addition, treatment-induced differences in the expression of ESR1 supports the idea that improved mammary growth with enhanced preweaning feeding corresponds with changes in ESR1 and PGR.

\section{ACKNOWLEDGMENTS}

The authors acknowledge Land O' Lakes, Inc. (St. Paul, MN) and Tom Earleywine (Land O' Lakes) for providing milk replacer and support during this trial. We also acknowledge grant support from USDA-NIFAAFRI (Washington, DC), 2016-67015-24575, Impact of Pre-Weaning Nutrition on Endocrine Induction of Mammary Development in Dairy Heifers awarded to R. M. Akers and 2016-67011-24703 (pre-doctoral fellowship to A. J. Geiger).

\section{REFERENCES}

Beaudry, K. L., C. L. M. Parsons, S. E. Ellis, and R. M. Akers. 2016 Localization and quantitation of macrophages, mast cells, and eosinophils in the developing bovine mammary gland. J. Dairy Sci. 99:796-804.

Berry, S. D., P. M. Jobst, S. E. Ellis, R. D. Howard, A. V. Capuco, and R. M. Akers. 2003. Mammary epithelial proliferation and estrogen receptor alpha expression in prepubertal heifers: effects of ovariectomy and growth hormone. J. Dairy Sci. 86:2098-2105.

Berry, S. D. K., T. B. McFadden, R. E. Pearson, and R. M. Akers 2001. A local increase in the mammary IGF-I:IGFBP-3 ratio mediates the mammogenic effects of estrogen and growth hormone. Domest. Anim. Endocrinol. 21:39-53.

Brown, E. G., M. J. Vandehaar, K. M. Daniels, J. S. Liesman, L. T. Chapin, J. W. Forrest, R. M. Akers, R. E. Pearson, and M. S. Nielsen. 2005. Effect of increasing energy and protein intake on mammary development in heifer calves. J. Dairy Sci. 88:595-603.

Capuco, A. V., and R. M. Akers. 2010. Management and environmental influences on mammary gland development and milk production. Pages 259-292 in Managing the Prenatal Environment to Enhance Livestock Productivity. P. L. Greenwood, A. W. Bell, P. E. Verce, and G. J. Viljoen, ed. Springer, the Netherlands.
Capuco, A. V., S. Ellis, D. L. Wood, R. M. Akers, and W. Garrett. 2002. Postnatal mammary ductal growth: three-dimensional imaging of cell proliferation, effects of estrogen treatment, and expression of steroid receptors in prepubertal calves. Tissue Cell $34: 143-154$

Daniels, K. M., A. V. Capuco, M. L. McGilliard, R. E. James, and R. M. Akers. 2009a. Effects of milk replacer formulation on measures of mammary growth and composition in Holstein heifers. J. Dairy Sci. 92:5937-5950.

Daniels, K. M., M. L. McGilliard, M. J. Meyer, M. E. Van Amburgh, A. V. Capuco, and R. M. Akers. 2009b. Effects of body weight and nutrition on histological mammary development in Holstein heifers. J. Dairy Sci. 92:499-505.

Drackley, J. K., B. C. Pollard, H. M. Dann, and J. A. Stamey. 2007. First-lacation milk production for cows fed control or intensified milk replacer as calves. J. Dairy Sci. 90(Suppl. 1):614. (Abstr.)

Ellis, S., R. M. Akers, A. V. Capuco, and S. Safayi. 2012. Bovine mammary epithelial cell lineages and parenchymal development. J. Anim. Sci. 90:1666-1673.

Geiger, A. J., C. L. Parsons, and R. M. Akers. 2016b. Feeding a higher plane of nutrition and providing exogenous estrogen increases mammary gland development in Holstein heifer calves. J. Dairy Sci. 99:7642-7653.

Geiger, A. J., C. L. Parsons, R. E. James, and R. M. Akers. 2016a. Growth, intake, and health of Holstein heifer calves fed an enhanced pre-weaning diet with or without exogenous estrogen. J. Dairy Sci. 99:3995-4004.

Heinrichs, A. J. 1993. Raising dairy replacements to meet the needs of the 21st century. J. Dairy Sci. 76:3179-3187.

Horwitz, K. B., Y. Koseki, and W. L. McGuire. 1978. Estrogen control of progesterone receptor in human breast cancer: Role of estradiol and antiestrogen. Endocrinology 103:1742-1751.

Khan, M. A., D. M. Weary, and M. A. G. von Keyserlingk. 2011. Invited review: Effects of milk ration on solid feed intake, weaning, and performance in dairy heifers. J. Dairy Sci. 94:1071-1081.

Meyer, M. J., A. V. Capuco, Y. R. Boisclair, and M. E. Van Amburgh 2006c. Estrogen-dependent responses of the mammary fat pad in prepubertal dairy heifers. J. Endocrinol. 190:819-827.

Meyer, M. J., A. V. Capuco, D. A. Ross, L. M. Lintault, and M. E. Van Amburgh. 2006a. Developmental and nutritional regulation of the prepubertal heifer mammary gland: I. Parenchyma and fat pad mass and composition. J. Dairy Sci. 89:4289-4297.

Meyer, M. J., A. V. Capuco, D. A. Ross, L. M. Lintault, and M. E. Van Amburgh. 2006b. Developmental and nutritional regulation of the prepubertal bovine mammary gland: II. Epithelial cell proliferation, parenchymal accretion rate, and allometric growth. J. Dairy Sci. 89:4298-4304.

Meyer, M. J., R. P. Rhoads, A. V. Capuco, E. E. Connor, A. Hummel, Y. R. Boisclair, and M. E. Van Amburgh. 2007. Ontogenic and nutritional regulation of steroid receptor and IGF-I transcript abundance in the prepubertal heifer mammary gland. J. Endocrinol. 195:59-66.

Paine, I. S., and M. T. Lewis. 2017. The terminal end bud: The little engine that could. J. Mammary Gland Biol. Neoplasia 22:93-108. https://doi.org/10.1007/s10911-017-9372-0.

Purup, S., M. Vestergaard, M. S. Weber, K. Plaut, R. M. Akers, and K. Sejrsen. 2000. Local regulation of pubertal mammary growth in heifers. J. Anim. Sci. 78(Suppl 3):36-47.

Radcliff, R. P., M. J. Vandehaar, L. T. Chapin, T. E. Pilbeam, D. K Beede, E. P. Stanisiewski, and H. A. Tucker. 2000. Effects of diet and injection of bovine somatotropin on prepubertal growth and first-lactation milk yields of Holstein cows. J. Dairy Sci. 83:23-29.

Russo, J., X. Ao, C. Grill, and I. H. Russo. 1999. Pattern of distribution of cells positive for estrogen receptor alpha and progesterone receptor in relation to proliferating cells in the mammary gland. Breast Cancer Res. Treat. 53:217-227.

Safayi, S., N. Korn, A. Bertram, R. M. Akers, A. V. Capuco, S. L. Pratt, and S. Ellis. 2012. Myoepithelial cell differentiation markers in prepubertal bovine mammary gland: Effect of ovariectomy. J. Dairy Sci. 95:2965-2976. 
Schams, D., S. Kohlemberg, W. Amselgruber, B. Berishan, M. W. Pfaffl, and F. Sinowatz. 2003. Expression and localization of oestrogen and progesterone receptors in the bovine mammary gland during development, function and involution. J. Endocrinol. 177:305-317.

Sejrsen, K. 1994. Relationships between nutrition, puberty and mammary development in cattle. Proc. Nutr. Soc. 53:103-111.

Soberon, F., E. Raffrenato, R. W. Everett, and M. E. Van Amburgh. 2012. Preweaning milk replacer intake and effects on long-term productivity of dairy calves. J. Dairy Sci. 95:783-793.

Thorn, S. R., S. Purup, M. Vestergaard, K. Sejrsen, M. J. Meyer, M. E. Van Amburgh, and Y. R. Boisclair. 2008. Regulation of mammary parenchymal growth by the fat pad in prepubertal dairy heifers: role of inflammation-related proteins. J. Endocrinol. 196:539-546.

Tucker, H. L. M., C. L. M. Parsons, S. Ellis, M. L. Rhoads, and R. M. Akers. 2016. Tamoxifen Impairs prepubertal mammary development and alters expression of estrogen receptor $\alpha$ (ESR1) and progesterone receptors (PGR). Domest. Anim. Endocrinol. 54:95-105.

Van Amburgh, M. E., D. M. Galton, D. E. Bauman, R. W. Everett, D. G. Fox, L. E. Chase, and H. N. Erb. 1998. Effects of three prepu- bertal body growth rates on performance of Holstein heifers during first lactation. J. Dairy Sci. 81:527-538.

Velayudhan, B. T., B. P. Huderson, S. E. Ellis, C. L. Parsons, R. C. Hovey, A. R. Rowson, and R. M. Akers. 2015. Ovariectomy in young prepubertal dairy heifers causes complete suppression of mammary progesterone receptors. Domest. Anim. Endocrinol. 51:8-18.

Weber, M. S., S. Purup, M. Vestergaard, R. M. Akers, and K. Sejrsen. 2000. Nutrition and somatotropin regulation of the mitogenic response of mammary cells to mammary tissue extracts. Domest. Anim. Endocrinol. 18:159-164.

Weber, M. S., S. Purup, M. Vestergaard, S. E. Ellis, J. ScndergardAndersen, R. M. Akers, and K. Sejrsen. 1999. Contribution of insulin-like growth factor (IGF)-I and IGF-binding protein-3 to mitogenic activity in bovine mammary extracts and serum. J. Endod. 161:356-373.

Woodward, T. L., W. E. Beal, and R. M. Akers. 1993. Cell interactions in initiation of mammary epithelial proliferation by oestradiol and progesterone in prepubertal heifers. J. Endocrinol. 136:149-157. 